\title{
技術論文
}

\author{
우주용 구조 재료의 초정밀 열팽창계수 측정시스템 설계 \\ 김홍일*, 한재흥**, 양호순 ***, 조창래****, 조혁진 $* * * *$, 김홍배****

\section{Design of High-precision CTE measurement System for the Structural Materials in Space Applications} \\ Hongil Kim*, Jae-Hung Han**, Hosoon Yang***, Changrae Cho****, \\ Hyokjin Cho**** and Hong-Bae Kim****
}

\begin{abstract}
Structures being used in space environment, should be designed to have minimum CTE(coefficient of thermal expansion) for the dimensional stability. Accurate CTE data of the materials are required to design the space structures consisting of various materials. There are uncertainties in the characteristics of materials even though the same manufacturing processes are applied. Therefore, it is needed to measure the thermal deformation of not only the material specimen but also substructures in simulated space environment, such as high vacuum condition. In this research, therefore, precise CTE measurement system using displacement measuring interferometer and vacuum chamber has been designed with uncertainty analysis of the measurements. This system can be used to measure the CTE of the specimen or thermal expansion of the substructure with varying size up to $50 \mathrm{~cm}$ in length. To measure the low CTE material, overall uncertainty of this system is expected under $0.01 \mathrm{ppm} / \mathrm{K}$.

\section{초 록}

우주용 구조물에 사용되는 재료는 치수 안정성을 위해서 열팽창계수를 최소화하도록 설계, 제작되어야 한다. 이를 위하여 우주용 재료 시편의 정밀한 열팽창계수를 측정하여, 그 재료의 열 특성에 대한 정확한 데이터를 확보할 필요가 있다. 그리고 시편뿐만 아니라 실제 사용될 구조물의 열 변형을 우주 환경에서 직접 측정할 필요가 있다. 따라서 본 연 구에서는 고진공에서 정밀한 변위 측정을 위하여 변위 측정 간섭계와 항우연의 보조 챔버 를 활용한 열팽창계수 측정 시스템을 설계하였다. 또한 본 측정 시스템은 길이 $500 \mathrm{~mm}$ 정 도의 긴 구조물의 열 변형을 측정할 수 있으며, 전체 시스템의 불확도는 $0.01 \mathrm{ppm} / \mathrm{K}$ 미만 이 되도록 설계되었다.
\end{abstract}

Key Words : Dimensional stability(치수 안정성), CTE(열팽창계수), Displacement measuring Interferometer(변위 측정 간섭계)

†2008년 4월 21일 접수 2008년 6월 30일 심사완료

* 정회원, 한국과학기술원 항공우주공학과 대학원

** 정회원, 한국과학기술원 항공우주공학과

교신저자, E-mail : jaehunghan@kaist.ac.kr

대전시 유성구 구성동 373-1번지

*** 정회원, 한국표준과학연구원

**** 정회원, 한국항공우주연구원

\section{I. 서 론}

최근 국내 우주 개발 사업이 활발히 진행되면 서, 극한 우주 환경에서도 재료와 구조물의 형상 을 유지할 수 있는 치수 안정성(Dimensional 
stability)이 우주용 구조물에 요구되고 있는데, 특 히 열 특성에 대한 선행 연구가 필요한 상황이다.

선진국에서는 재료의 열 특성 데이터를 체계 적으로 관리, 이용하여 왔고, 오래전부터 데이터 수집을 위해 여러 가지 방법으로 열팽창계수를 측정하여왔다. 보통 시편의 길이 변화를 측정하 는 원리에 따라 크게 팽창계법(Dilatometry), 광 학적 방법(Optical method), 회절법(Diffraction technique)등으로 구분할 수 있다[1]. 팽창계법은 가장 오래되고 일반적인 방법으로 온도가 조절되 고 있는 시편에 일정한 압력을 주는 푸쉬로드가 접촉되어있고, 이 푸쉬로드를 통해 시편의 변형 을 LVDT (Linear variable differential transformer)와 같은 센서로 측정하는 방법이다. 많은 상 용 열팽창계수 측정기가 팽창계법을 이용하여 제 작되었다. 광학적 방법은 보통 광 간섭 효과를 이용하여 시편의 길이 변화를 측정한다. 이 방법 은 시편에 직접 푸쉬로드가 부착되어야 하는 팽 창계법과 비교하여, 푸쉬로드의 열 변형에 의한 영향을 줄일 수 있고, 시편과 접촉을 최소화 할 수 있는 장점이 있어 보다 정밀한 측정을 요구하 는 측정 시스템에 많이 사용되고 있다. 아래 그 림 1 은 미국 PMIC사의 열팽창계수 측정 시스템 의 개략도이다. 진공 챔버 내에 위치한 시편의 미세한 길이 변화를 시편의 양 끝에 부착된 거울 에서 반사된 레이저의 간섭광을 통하여 측정하는 원리이다. 이 시스템의 전체 열팽창계수 측정 불 확도(uncertainty)는 $0.01 \mathrm{ppm} / \mathrm{K}$ 로 알려져 있다 [2]. 회절법은 $\mathrm{X}^{-}$레이를 사용하여 재료의 격자 구 조의 변화를 측정하는 방법이다. 이 방법은 보통 기계적으로나 광학적으로 측정하기 힘든 파우더 등의 작고 약한 재료의 열팽창을 측정하기 위해 사용된다.

앞서 언급한 열팽창 측정 방법은 보통 규격화

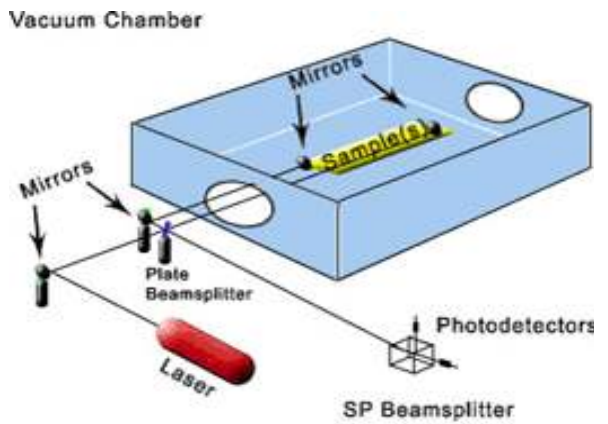

그림 1. 미켈슨 간섭계를 사용한 열팽창계수 측정 장치
된 시편의 열팽창계수를 측정하는데 사용되는 방 법이다. 하지만 우주용 구조물에 많이 사용되는 복합재료는 제작 공정의 성형 조건, 실험 환경 등에 따라 물성치의 편차가 크다. 또한 동일한 성형 조건으로 제작된 구조물의 경우에도 물성치 의 편차가 크게 나타나기도 한다. 따라서 이들 재료를 우주용 구조물에 적용을 하기 위해 시편 단위의 열 특성 측정뿐 만 아니라, 우주 환경과 유사하게 모사된 고진공 환경에서의 실제 구조물 에 사용될 부재의 열 변형 측정도 필요하다. 따 라서 본 연구에서는 우주 환경을 모사하고, 모사 된 우주 환경에서의 시편 혹은 구조물의 정밀한 변위 및 열팽창계수 측정을 위한 실험 장치를 설 계하는 것을 목적으로 하였다. 실험 장치는 진공 과 우주 환경 모사에 적용이 용이한 광학 간섭계 를 사용하여, $0.01 \mathrm{ppm} / \mathrm{K}$ 의 불확도를 가지도록 설계하였다.

\section{II. 본 론}

\section{1 열팽창계수의 정의}

모든 재료의 온도에 의한 열팽창은 시편의 길 이 변화 등으로 정량화 된다. 그래서 간단히 재 료의 열팽창계수 (CTE : Coefficient of thermal $\left.\mathrm{expa}^{-} \mathrm{nsion}\right)$ 는 온도 변화에 따른 시편의 길이 변화율로 정의된다. 하지만 넓은 온도 영역에서 사용되는 재료는 온도에 따라 열팽창 정도가 변 화하므로, 측정 조건을 고려한 엄밀한 열팽창계 수 정의가 필요한 경우가 있다.

열팽창계수는 측정온도범위 $\left(\Delta T=T_{2}-T_{1}\right)$ 에서 정의되는 평균열팽창계수 $\left(\alpha_{m}\right)$ 와 특정 온도에서 정의되는 참 열팽창계수 $\left(\alpha_{t}\right)$ 로 크게 2 가지로 구 분할 수 있다. 식(1)은 평균열팽창계수의 정의이 다. 측정온도범위 $(\Delta T)$ 에서의 시편의 길이변화 $(\Delta L)$ 를 온도차이 $\left(T_{2}-T_{1}\right)$ 로 나눈 것이다. 따라서 두 온도 사이에서 발생하는 시편의 변형을 평균 한 개념으로 볼 수 있다(그림 2).

$$
\begin{aligned}
& \alpha_{m}\left(T_{2}, T_{1}, T_{0}\right)=\frac{1}{L\left(T_{0}\right)} \frac{L\left(T_{2}\right)-L\left(T_{1}\right)}{T_{2}-T_{1}}=\frac{1}{L} \frac{\Delta L}{\Delta T} \\
& L=L\left(T_{o}\right) \\
& L: \text { 시편 초기 길이, 기준 온도 }\left(T_{0}\right) \text { 에서의 길이 }
\end{aligned}
$$

이 때, 식(2)와 같이 필요에 따라 기준 온도를 $T_{0}$ 가 아니라, $T_{1}$ 으로 정한 수정 열팽창계수 $\left(\alpha_{m^{*}}\right)$ 를 사용하기도 한다.

$$
\alpha_{m^{*}}\left(T_{2}, T_{1}\right)=\frac{1}{L\left(T_{1}\right)} \frac{L\left(T_{2}\right)-L\left(T_{1}\right)}{T_{2}-T_{1}}
$$






그림 2. 온도에 따른 시편의 길이변화

한편, 식(3)과 같이 온도 범위가 아닌 특정 온 도의 열팽창계수를 정의하기도 하는데, 이를 참 열팽창계수라고 한다. 참 열팽창계수는 특정 온 도 $(T)$ 에서의 열팽창을 시편 초기 길이로 나눈 것이다. 간단히 온도에 따른 열팽창의 미분 값으 로 생각할 수 있다(그림 2).

$$
\alpha_{t}(T)=\lim _{\tau \rightarrow T} \frac{1}{L(T)} \frac{L(\tau)-L(T)}{\tau-T}=\left.\frac{1}{L(T)} \frac{d L}{d T}\right|_{\tau=T}
$$

또한 필요에 따라 기준 온도를 $T_{o}$ 로 하는, 수정 참 열팽창계수 $\left(\alpha_{t^{*}}\right)$ 를 사용하기도 한다(식(4)).

$$
\alpha_{t^{*}}(T)=\lim _{\tau \rightarrow T} \frac{1}{L\left(T_{0}\right)} \frac{L(\tau)-L(T)}{\tau-T}=\left.\frac{1}{L\left(T_{0}\right)} \frac{d L}{d T}\right|_{\tau=T}
$$

참 열팽창계수는 넓은 온도 범위에서 시편의 열팽창계수가 어떻게 변화하는지 살펴볼 때 사용 한다. 그래서 온도를 지속적으로 변화해가면서 측정하는데, 그로 인해 시편 전체적으로 온도가 균일하지 않을 수 있으며, 넓은 온도 범위로 인 해 측정 불확도가 평균열팽창계수의 경우보다 상 대적으로 떨어지는 단점이 존재한다. 그리고 보 통의 금속, 복합재료는 수십도 정도의 온도 범위 에서 열팽창계수가 거의 일정하다. 따라서 본 연구에서는 측정 온도 구간에서 재료의 열팽창계 수가 일정하다고 판단하고, 평균열팽창계수 정의 를 이용하여, 설계요구조건을 구하고, 불확도 예 측을 수행하였다.

\section{2 설계요구조건}

최근 우주용 망원경이나 대형 안테나 등에 복 합재료를 많이 사용하고 있다. 하지만 복합재료 의 경우 제작 공정 및 형상에 따라 물성치가 다 르기 때문에, 시편 단위의 열팽창계수 측정뿐 만 아니라, 복합재료로 제작된 실제 구조물의 열팽 창을 직접 측정하여 설계를 검증할 필요가 있다. 이를 위해 본 시스템은 측정 가능한 시편의 길이

\begin{tabular}{|c|c|c|}
\hline \multicolumn{2}{|c|}{ 설계 요구 사항 } & 관련 장비 \\
\hline \multirow[b]{2}{*}{ 고진공 } & \multirow[b]{2}{*}{$<1 \times 10^{-5}$ torr } & 항우연 보조챔버 \\
\hline & & $\begin{array}{c}\text { 진공 }<1 \times 10^{-6} \text { torr } \\
\text { Dia. } 1.5 \mathrm{~m}\end{array}$ \\
\hline 온도측정 & $\begin{array}{c}\text { 온도측정 } \\
\text { 표준불확도 } \\
u_{\Delta T}=0.27 \mathrm{~K}\end{array}$ & $\begin{array}{c}\text { 열전대 시스템 } \\
\text { Simatic } \\
\text { SM331 7PF10-0AB0 }\end{array}$ \\
\hline 시편 가열 & $\Delta T>60^{\circ} \mathrm{C}$ & 파워서플라이+열터널 \\
\hline \multirow[b]{2}{*}{$\begin{array}{l}\text { 정밀 } \\
\text { 변위 측정 }\end{array}$} & \multirow{2}{*}{$\begin{array}{c}\text { 변위 측정 } \\
\text { 표준불확도 } \\
u_{\Delta L}<10 \mathrm{~nm}\end{array}$} & 변위 측정 간섭계 \\
\hline & & $\begin{array}{l}\text { 시스템해상도 }(0.15 \mathrm{~nm})+ \\
\text { 각종 외란에 의한 불확도 }\end{array}$ \\
\hline$\| \wedge$ & \multicolumn{2}{|c|}{$\begin{array}{l}\text { 합성표준불확도 }\left(u_{c}\right)<0.01 \mathrm{ppm} / \mathrm{K} \\
\text { 최대 측정 가능 시편 길이 }=500 \mathrm{~mm}\end{array}$} \\
\hline
\end{tabular}

표 1. 설계 요구 사항 및 관련 장비

를 최대 $500 \mathrm{~mm}$ 정도로 하여, 우주에서 사용할 실제 구조물의 열팽창을 관찰할 수 있도록 할 필 요가 있다. 그리고 우주환경을 모사하기 위하여 $1 \times 10^{-5}$ torr. 이상의 고진공과 $60^{\circ} \mathrm{C}$ 이상의 온도 변화를 인가 할 수 있는 진공 챔버를 사용하여야 한다. 우주용 복합재료 구조는 치수 안정성을 위 해, 열팽창계수가 0 에 가깝도록 설계를 하고 있 다. 따라서 이들 복합재료 구조물의 성능 검증을 위해서 매우 정밀한 측정 시스템이 필요하다. 현 재 대구경 망원경 등의 재료로 많이 쓰이는 Zerodur와 같은 유리재질은 상온에서 0.01 $\mathrm{ppm} / \mathrm{K}$ 정도로 매우 낮은 열팽창계수를 가지고 있으므로, 본 측정 시스템도 Zerodur 수준으로 치수 안정성이 뛰어난 복합재료의 열팽창계수 혹 은 변형을 측정할 수 있도록 하여야 한다. 이를 위해 전체 시스템의 열팽창계수의 불확도가 0.01 $\mathrm{ppm} / \mathrm{K}$ 미만으로 구성되어야 하고, 복합재료 구 조물의 정밀한 길이 변화를 측정하기 위해 변위 측정의 불확도는 $10 \mathrm{~nm}$ 미만이 되어야 한다. 아 래 표 1 은 열팽창계수 측정 시스템의 설계 요구 사항과 사용할 수 있는 관련 장비를 정리한 것이 다. 본 연구에서는 본격적인 시스템 설계에 앞서, 열팽창계수의 불확도 예측을 통해 관련 장비의 성능이 설계 요구 사항에 맞는지 확인하였다.

\section{3 불확도 예측}

평균열팽창계수를 구하기 위해서 식(1)로부터 알 수 있듯이 필요한 입력량은 시편의 초기 길이 $(L)$, 시편의 길이변화 $(\Delta L)$, 온도변화 $(\Delta T)$ 다. 이들 입력량의 불확도를 통해 평균열팽창계수의 합성 표준불확도를 구하여 보자.

식(1)을 각각의 입력량에 대하여 테일러 전개 를 수행하면, 아래 식(5)와 같다. 


$$
\delta \alpha_{m}=\left(\frac{\partial \alpha_{m}}{\partial L}\right) \delta L+\left(\frac{\partial \alpha_{m}}{\partial \Delta L}\right) \delta \Delta L+\left(\frac{\partial \alpha_{m}}{\partial \Delta T}\right) \delta \Delta T
$$

식(5)로부터 불확도 전파법칙[3]을 적용하여 합성 표준불확도를 구할 수 있다(식(6)).

$u_{c}=$

$$
\sqrt{\left(\frac{\partial \alpha_{m}}{\partial L}\right)^{2} u_{L}^{2}+\left(\frac{\partial \alpha_{m}}{\partial \Delta L}\right)^{2} u_{\Delta L}^{2}+\left(\frac{\partial \alpha_{m}}{\partial \Delta T}\right)^{2} u_{\Delta T}^{2}}
$$

이 경우 감도계수는 식(7)과 같다. 위 결과를 이 용하여, 시편의 길이나 측정 온도 범위에 따라 합성표준불확도가 어떻게 변하는지 알 수 있다.

$$
\begin{gathered}
\left(\frac{\partial \alpha_{m}}{\partial L}\right)=-\frac{1}{L^{2}} \frac{\Delta L}{\Delta T}=-\frac{\alpha}{L} \\
\left(\frac{\partial \alpha_{m}}{\partial \Delta L}\right)=\frac{1}{L \Delta T} \\
\left(\frac{\partial \alpha_{m}}{\partial \Delta T}\right)=-\frac{1}{\Delta T^{2}} \frac{\Delta L}{L}=-\frac{\alpha}{\Delta T}
\end{gathered}
$$

또한 시스템에 사용하는 센서가 설계요구조건을 만족하는지 확인할 수 있다. 이 때, 온도는 한국 항공우주연구원 보조챔버에서 사용할 열전대 시 스템(Simatic SM331 7PF10-0AB0, 열전대 탐침 5TC-TT- T-30-500)을 사용하고, 시편의 초기 길 이는 전자식 버니어 캘리퍼스를 사용한 것을 가 정하였다. 그리고 시편 길이 변화 측정 불확도는 $10 \mathrm{~nm}$ 로 정하였다. 아래 표 2는 CTE가 $0.01 \mathrm{ppm}$ $/ \mathrm{K}$ 인 Zerodur를 측정한다고 할 때, 시편의 길이, 측정 온도 범위에 따른 합성표준불확도이다. 표 2 의 불확도 예측 결과를 보면, 시편의 길이가 길 고, 측정 시에 온도차이가 클수록, 그에 비례하여 열팽창계수의 불확도가 작아지는 것을 확인할 수 있다. 따라서 Zerodur와 같이 매우 작은 $\mathrm{CTE}$ 를 가진 재료의 실험을 위해서는 시편의 길이와 온 도 범위를 크게 함으로써 정밀한 측정이 가능하 다. 한편 이 때 길이 변화 측정의 불확도 $\left(u_{\Delta L}\right)$ 가 합성표준불확도 $\left(u_{c}\right)$ 에 미치는 영향이 가장 큰 것 을 확인 할 수 있었다(표 3). 따라서 열팽창계수 가 작은 재료의 정밀 측정을 위해서는 길이 변화 측정의 불확도를 줄이는 것이 필요한 것을 확인 할 수 있었다. 앞서 표 2의 불확도 예측 결과는 변위 측정의 불확도가 최대 $10 \mathrm{~nm}$ 라고 가정하고 계산 한 것으로, 변위 측정의 불확도가 상당히 커서, 시편의 길이가 짧거나, 온도 차이가 적을 때는, 실험 결과를 신뢰하지 못할 정도로 불확도 가 컸다. 변위 측정 간섭계의 불확도가 $10 \mathrm{~nm}$ 일

\begin{tabular}{|c|c|c|c|c|c|}
\hline CTE & \multicolumn{2}{|c|}{$0.01[\mathrm{ppm} / \mathrm{K}]$} & $\mathrm{u}(\Delta L)$ & \multicolumn{2}{|c|}{$\begin{array}{c}\text { 최대 } \\
10 \mathrm{~nm}\end{array}$} \\
\hline $\mathrm{u}(\mathrm{L})$ & \multicolumn{2}{|c|}{$0.005 \mathrm{~mm}$} & $\mathrm{u}(\Delta t$ & \multicolumn{2}{|c|}{$0.27 \mathrm{~K}$} \\
\hline \multirow{2}{*}{\multicolumn{2}{|c|}{$\mathrm{uc}[\mathrm{ppb} / \mathrm{K}]$}} & \multicolumn{4}{|c|}{ 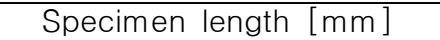 } \\
\hline & & 10 & 100 & 300 & 500 \\
\hline \multirow{6}{*}{$\begin{array}{l}\Delta T \\
{\left[{ }^{\circ} \mathrm{C}\right.}\end{array}$} & $\overline{1}$ & 1000 & 100.0 & 33.33 & 20.00 \\
\hline & 10 & 100.0 & 10.00 & 3.334 & 2.000 \\
\hline & 20 & 50.07 & 5.007 & 1.669 & 1.001 \\
\hline & 30 & 33.44 & 3.344 & 1.115 & 0.669 \\
\hline & 40 & 25.14 & 2.515 & 0.838 & 0.503 \\
\hline & 50 & 20.18 & 2.018 & 0.673 & 0.404 \\
\hline
\end{tabular}
때는, 표 4의 결과에서 알 수 있듯이, 합성표준불 확도가 시편 $\mathrm{CTE}$ 의 $6.69 \%$ 이기 때문에, 측정 정 밀도가 충분하지 않지만, 변위 측정 간섭계의 불
표 2. 불확도 예측 결과

표 3. 합성표준불확도에 각 입력량의 기여도

\begin{tabular}{c|c||c|c|c|c}
\hline \hline \multirow{2}{*}{$\Delta T=30^{\circ} \mathrm{C}$} & \multicolumn{4}{|c}{ Specimen length [mm] } \\
\cline { 2 - 5 } & 10 & 100 & 300 & 500 \\
\hline \hline \multirow{2}{*}{ uncertainty [ppb/K] } & 33.4 & 3.34 & 1.11 & 0.67 \\
\hline \hline \multirow{2}{*}{ Input } & $\begin{array}{c}\text { Specimen } \\
\text { length }\end{array}$ & 0.00 & 0.00 & 0.00 & 0.00 \\
\cline { 2 - 6 } & $\begin{array}{c}\text { Length } \\
\text { change }\end{array}$ & 33.3 & 3.33 & 1.11 & 0.67 \\
\cline { 2 - 6 } & $\begin{array}{c}\text { Temperature } \\
\text { change }\end{array}$ & 2.70 & 0.27 & 0.09 & 0.05 \\
\hline \hline
\end{tabular}

표 4. 변위 측정 불확도에 따른 합성표준불확도

\begin{tabular}{c|c|c}
\hline \hline \multicolumn{2}{c}{$\Delta T=50^{\circ} \mathrm{C}$} & \multicolumn{2}{c}{ Specimen length $=500[\mathrm{~mm}]$} \\
\hline \multicolumn{2}{c}{$\mathrm{CTE}=0.01[\mathrm{ppm} / \mathrm{K}]=10[\mathrm{ppb} / \mathrm{K}]$} \\
\hline \hline $\mathrm{u}(\Delta L)[\mathrm{nm}]$ & $\mathrm{uc}[\mathrm{ppb} / \mathrm{K}]$ & $\mathrm{uc} / \mathrm{CTE}[\%]$ \\
\hline 1 & 0.086 & 0.86 \\
\hline 2 & 0.144 & 1.44 \\
\hline 5 & 0.338 & 3.38 \\
\hline 10 & 0.669 & 6.69 \\
\hline \multicolumn{3}{|c}{}
\end{tabular}

확도가 $1 \mathrm{~nm}$ 로 작아지면, 합성표준불확도가 시편 $\mathrm{CTE}$ 의 $0.86 \%$ 정도로 충분한 측정 정밀도를 확보 할 수 있음을 확인하였다. 따라서 변위 측정 간 섭계를 사용하고, 적절한 환경 조절을 통해 우연 효과로 인한 불확도를 줄일 수 있다면, 훨씬 정 밀한 열팽창계수 측정이 가능할 것을 예상할 수 있다. 결론적으로 본 연구에서 주어진 관련 장비 를 적절히 사용하면, Zerodur와 같이 매우 작은 열팽창계수를 갖는 재료에 대해서도 신뢰할 만한 측정 결과를 얻을 수 있음을 확인하였다.

\section{4 변위 측정 간섭계(DMI) 원리}

보다 정밀한 열팽창계수 측정을 위해서, 본 연 구에서는 여러 장점(표 5)을 가지는 변위 측정 


\section{표 5. 변위 측정 간섭계의 장점}

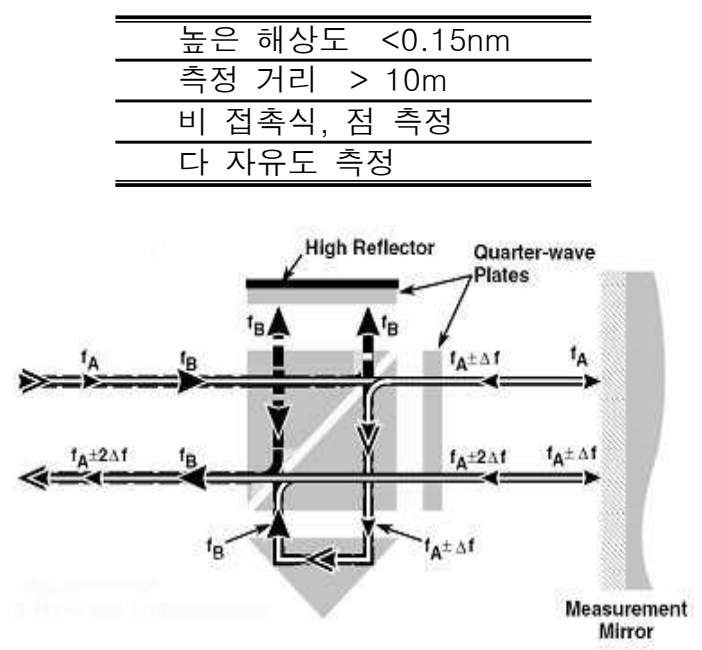

그림 3. Plane mirror Interferometer[4]

간섭계(DMI: Displacement Measuring Interferometer)를 사용하기로 하였다. 변위 측정 간섭계 의 높은 해상도는 작은 시편 길이 변화를 측정하 는데 적합하며, 비 접촉식으로, 긴 거리에서도 측 정가능하기 때문에, 진공 챔버 내부에서 측정하 기에 유리하다고 판단되었다. 변위 측정 간섭계 는 듀얼 모드 헤테로다인 레이저 $(\mathrm{HeNe})$ 와 간섭 계를 이용하여 변위를 측정하는 시스템으로, 듀 얼 모드 헤테로다인 레이저는 약 $3.4^{\sim} 4.0 \mathrm{MHz}$ 의 주파수를 가지며 수직으로 편광된 측정광 $\left(f_{A}\right)$ 과 기준광 $\left(f_{B}\right)$ 을 생성한다. 이렇게 생성된 레이저는 광 분할기를 통해 나눠져, 각각 간섭계를 거치면 서, 측정 기준 거울과 시편의 거리에 따른 간섭 광을 생성한다. 그리고 이 간섭광은 거리로 환 산이 된다. 그림 3 은 평면거울용 간섭계의 원리 를 설명한 것이다. 측정광은 간섭계 내부의 편광 광 분할기(PBS: Polarized beam spliter)에서 반 사되지 않고, 그대로 진행하여 측정하고자 하는 거울에 도달한 후, 되돌아오는 과정에서 발생된 도플러 효과에 의해 주파수가 변화하게 된다. 반 면에 기준광은 편광 광 분할기에서 반사되어 간 섭계 내부에서 자신의 주파수를 유지하며 진행하 게 된다. 이렇게 분리된 측정광과 기준광은 간섭 계를 나오면서 다시 하나로 합쳐져 리시버로 들 어가게 된다. 그 후 리시버와 레이저에서 측정된 주파수 차이 $(\Delta f)$ 를 위상측정기를 통해 비교를 하 게 되고, 이렇게 측정된 위상 차이는 적분을 통 해 시간에 따른 변위 $(x(t))$ 로 환산된다(식(8), (9)). 여기서 $\mathrm{n}$ 은 굴절률, $\lambda$ 는 기준광의 파장, $v$ 는 물체의 속도이다.

$$
\begin{gathered}
2 \Delta f=4 n v / \lambda[\mathrm{Hz}] \\
x(t)=\int_{0}^{t} \Delta f \lambda / 2 n d \tau
\end{gathered}
$$

\section{5 열팽창계수 측정 시스템 설계}

\subsection{1. 변위 측정 간섭계의 구성}

이번 연구에 사용된 변위 측정 간섭계는 앞에 서 언급한대로, 헤테로다인 방법을 사용한 레이 저 간섭계로 듀얼 모드 레이저헤드, 광 분할기 (beam splitter), 2개의 평면 유리 간섭계(plane mirror interferometer), 리시버와 PCI 보드로 구 성되어있고, 이들을 실험 목적에 맞도록 적절하 게 구성을 하였다. 변위 측정 간섭계는 다 자유 도 측정이 가능하기 때문에, 그림 4 에서 보듯이 광 분할기와 2 개의 간섭계를 사용하여, 동일한 베이스에 장착된 기준거울과 시편거울의 변위를 동시에 측정 할 수 있도록 하였다. 레이저헤드에 서 나온 레이저는 광 분할기에 의해 나눠지며, 이렇게 나눠진 레이저가 각각 기준거울과 시편거 울을 향하게 된다. 그리고 그 경로에서 생성된 간섭광이 각각 리시버로 들어갈 수 있도록, 반사 경을 구성하였다. 이런 방식으로 변위 측정 간섭 계를 구성하면, 시편과 기준면이 동일 베이스에 장착되어 열팽창에 의한 기준거울의 움직임을 식 (10)과 같이 시편거울까지의 거리 $\left(L_{t a r}\right)$ 에서 기준 거울까지의 거리 $\left(L_{r e f}\right)$ 를 뺌으로써 시편의 길이 변화 $(\Delta L)$ 를 구할 수 있다.

$$
\Delta L=L_{t a r}-L_{r e f}
$$

\subsection{2. 전체 시스템 구성}

본 측정 시스템은 진공 챔버와 광학 테이블, 레이저 및 레이저 캐니스터, 간섭계, 시편 받침과 열터널로 구성된다(그림 5). 진공 챔버는 $1 \times 10^{-6}$ torr.까지 진공 상태를 유지할 수 있는 한국항공

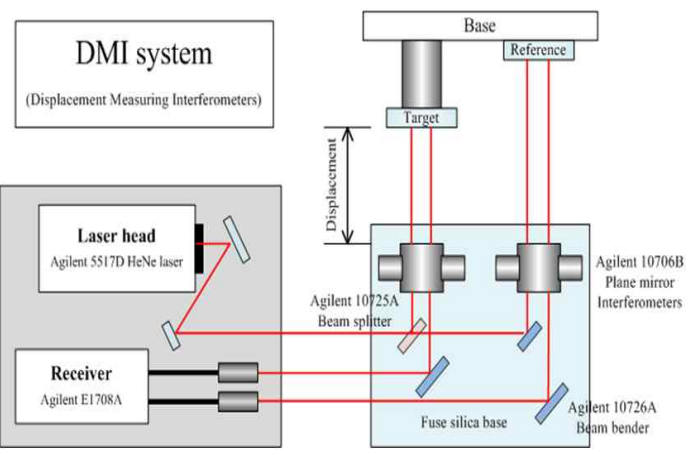

그림 4. 변위 측정 간섭계 구성 


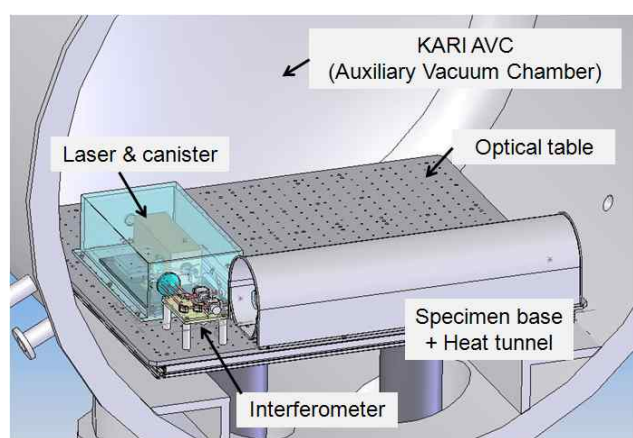

그림 5. 정밀 열팽창계수 측정 시스템

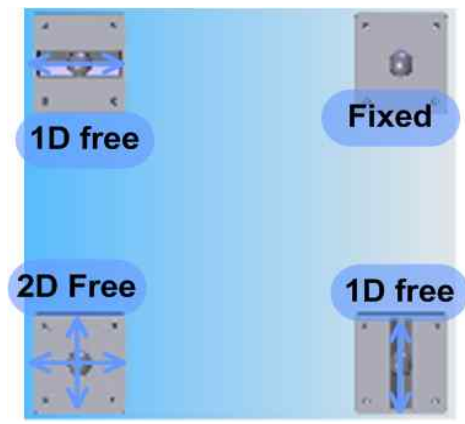

그림 6. 키네메틱 커플링

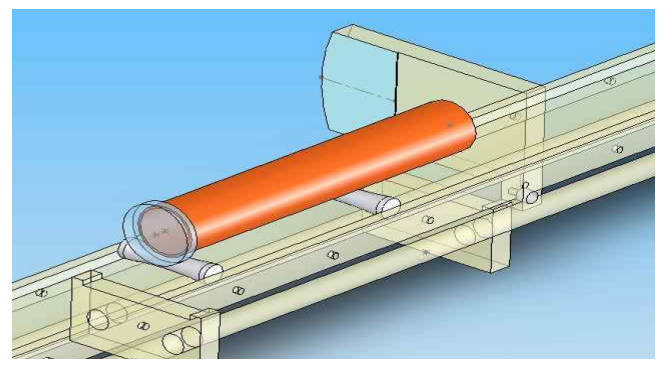

그림 7. 시편 받침과 장착된 시편

우주연구원의 보조 챔버를 활용할 계획이다. 그 리고 광학 테이블은 보조 챔버 내부에 설치되며, 보조 챔버와 독립된 질량과 연결되어, 챔버에서 발생하는 여러 가지 진동에서 독립되도록 하였 다. 또한 일반적으로 광학 실험에 사용되는 테이 블에 준하는 편평도를 가지도록 설계되었다. 그 리고 큰 온도 변화에도 스스로 편평도를 유지할 수 있도록 광학 테이블은 다리와 키네메틱 커플 링을 통하여 연결되도록 하였다(그림 6). 열터널 의 경우 진공에서 열테이프에 의해 발생하는 열 을 복사를 통해 터널 내부의 시편으로 전달할 수 있도록 하였다. 시편 받침대는 시편을 수평으로 놓도록 설계되었다. 높은 온도 환경에서도 시편

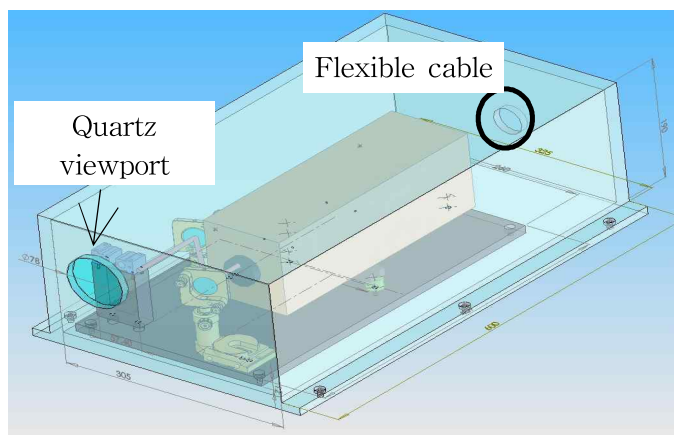

그림 8. 레이저 캐니스터

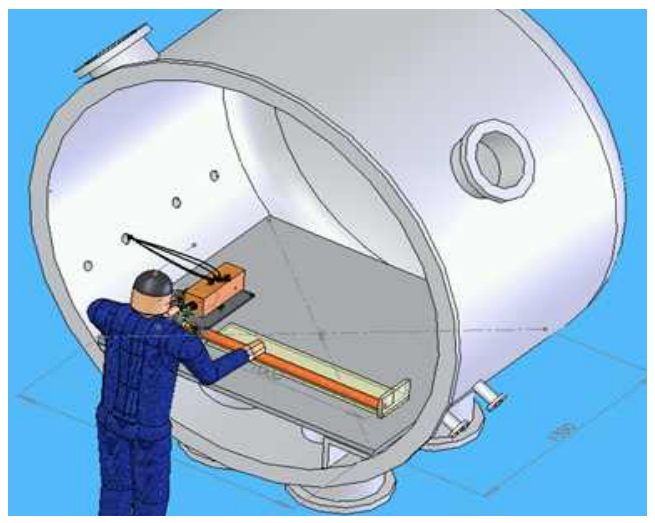

그림 9. 광 정렬 편의성 검토

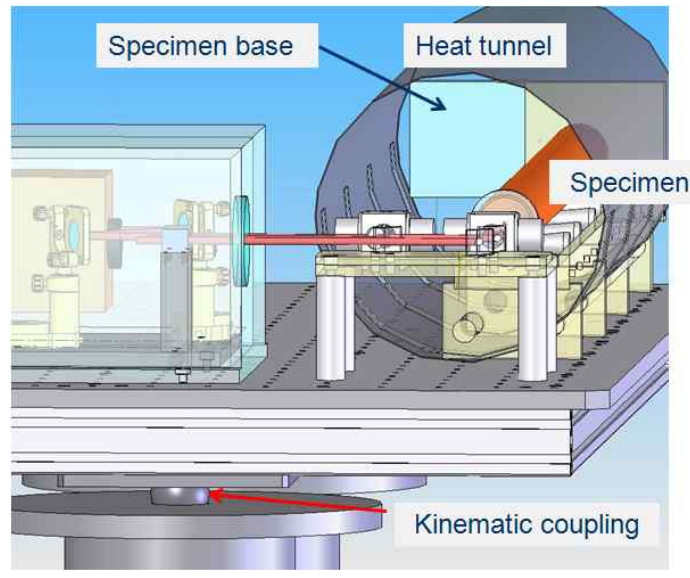

\section{그림 10. 광로 간섭 검토}

의 길이 방향 변형 측정에 영향이 발생하지 않도 록, 열 변형이 작은 Fused silica (CTE < 1 $\mathrm{ppm} / \mathrm{K}$ )를 사용하였으며, 시편이 시편 받침에 점 접촉을 유지하도록 롤러를 설치하여 시편 받침에 의한 저항을 최소화하였다. 그리고 기준거울 면 이 시편이 장착될 면에 직접 코팅되어, 기준거울 
과 시편이 동일 베이스에 있도록 설계하였다(그 림 7). 그리고 우리가 사용할 듀얼 모드 레이저 (Agilent 5517D)의 경우, 진공에서 사용할 수 없 기 때문에, 레이저헤드를 챔버 내에서 상압으로 유지하기 위해 캐니스터를 설계하였다. 캐니스터 는 레이저와 간섭계의 정렬을 위해, 뚜껑을 여닫 을 수 있도록 설계되었으며, 유리로 만들어진 뷰 포트를 통해 레이저가 통할 수 있도록 하였다. 그리고 레이저의 전원은 캐니스터 뒤에 연결된 플렉시블 케이블을 통하여 상온, 1 기압 상태를 유지하며 외부와 연결된다(그림 8). 전체 시스템 의 위치는 레이저와 간섭계, 시편의 정렬을 쉽게 하기 위해서 그림 9 와 같이 작업성을 고려하여 설계되었다. 실험을 수행하기 위한 대부분의 작 업은 기준거울과 시편거울을 간섭계와 레이저에 정렬하는 것이다. 따라서 기준거울과 시편거울이 놓일 시편받침대를 챔버 입구에 가까이 위치하게 하여, 작업자가 챔버 내부로 들어갈 일이 없도록 하였다. 전체 시스템을 설계한 후, 그림 10 과 같 이 광로 간섭도 검토하였다.

\section{III. 결 론}

본 연구를 통해서 우주용 복합재료 열팽창계 수 측정 시스템을 설계를 하였다. 우주 환경의 모사를 위해 항우연의 진공 챔버를 활용할 수 있 도록 시스템을 구성하였으며, 정밀한 열팽창계수 의 측정을 위해 헤테로다인 레이저 간섭계를 사
용하기로 하였다. 이를 위해 레이저 캐니스터, 시 편 받침, 열터널, 광학 테이블 등의 각 부분을 설 계하였으며, 전체 시스템의 광로 간섭 및 작업성 확인을 수행하였다. 추후에 이 설계 결과를 바탕 으로 정밀 열팽창계수 측정 시스템을 구성할 것 이다.

\section{후 기}

본 연구는 한국표준과학연구원의 위탁과제 '위 성 카메라용 광기계 구조물의 치수 안정성 증대 에 관한 연구' 의 연구비 지원에 의한 연구 결과 입니다.

\section{참고문헌}

1) J. D. James, J. A. Spittle, S. G. R. Brown and R. W. Evans, "A review of measurement techniques for the thermal expansion coefficient of metals and alloys at elevated temperatures", Measurements Science and Technology, Vol.12, pp. R1-R15, 2001

2) http://pmiclab.com/02_thermal_expansion. html

3) 한국표준과학연구원, "측정 불확도 표현 지 침", KRISS-99-070-SP

4) Laser and Optics User's Manual, Agilent Tech. 2002 